\title{
Distribution of tick-borne diseases in China
}

\author{
Xian-Bo Wu' ${ }^{1}$, Ren-Hua Na², Shan-Shan $\mathrm{Wei}^{2}$, Jin-Song Zhu ${ }^{3}$ and Hong-Juan Peng ${ }^{2 *}$
}

\begin{abstract}
As an important contributor to vector-borne diseases in China, in recent years, tick-borne diseases have attracted much attention because of their increasing incidence and consequent significant harm to livestock and human health. The most commonly observed human tick-borne diseases in China include Lyme borreliosis (known as Lyme disease in China), tick-borne encephalitis (known as Forest encephalitis in China), Crimean-Congo hemorrhagic fever (known as Xinjiang hemorrhagic fever in China), Q-fever, tularemia and North-Asia tick-borne spotted fever. In recent years, some emerging tick-borne diseases, such as human monocytic ehrlichiosis, human granulocytic anaplasmosis, and a novel bunyavirus infection, have been reported frequently in China. Other tick-borne diseases that are not as frequently reported in China include Colorado fever, oriental spotted fever and piroplasmosis. Detailed information regarding the history, characteristics, and current epidemic status of these human tick-borne diseases in China will be reviewed in this paper. It is clear that greater efforts in government management and research are required for the prevention, control, diagnosis, and treatment of tick-borne diseases, as well as for the control of ticks, in order to decrease the tick-borne disease burden in China.
\end{abstract}

Keywords: Ticks, Tick-borne diseases, Epidemic, China

\section{Review}

Ticks can carry and transmit viruses, bacteria, rickettsia, spirochetes, protozoans, Chlamydia, Mycoplasma, Bartonia bodies, and nematodes [1,2]. Approximately 10 genera of ticks, 119 species including 100 species of Ixodidae and 19 species of Argasidae, have been identified in China [1].

Tick-borne diseases are a major contributor to vectorborne diseases, and are distributed worldwide. They are mainly natural focal diseases, and most often occur in forests, bushes, and semi-desert grasslands. Globally, the number of distinct and epidemiologically important tickborne diseases, including tick-borne encephalitis, Kyasanur forest disease, Crimean-Congo hemorrhagic fever, and Rocky Mountain spotted fever, has increased considerably over the last 30 years [3]. The vast territory, complex geography, and climate of China contribute to the abundance and diversity of ticks, thus tick-borne diseases are prevalent in most parts of China and seriously affect human health [1]. In recent years, tick-borne diseases have occurred in almost all Provinces/Autonomous Regions/Municipalities $(\mathrm{P} / \mathrm{A} / \mathrm{M})$ in China and the infection rate continues to rise

\footnotetext{
* Correspondence: floriapeng@hotmail.com

2Department of Pathogen Biology, School of Public Health and Tropical Medicine, Southern Medical University, Guangzhou, Guangdong 510515, China

Full list of author information is available at the end of the article
}

(Table 1) [2,4]. Continuous reports of emerging tick-borne disease cases in Shandong, Henan, Hebei, Anhui, and other provinces demonstrate the rise of these diseases throughout China (Table 1) [4]. Therefore, furthering knowledge of the epidemic status and the distribution of tick-borne diseases in China is extremely urgent for the prevention and control of these diseases, as well as for reducing the disease burden.

\section{Common tick-borne zoonoses in China Lyme borreliosis}

Lyme borreliosis (LB), also called Lyme disease in China, is a natural focal disease caused by Borrelia burgdorferi sensu lato. LB usually manifests as an acute disease. It only becomes chronic in a small proportion of patients, if left untreated. It is named after Lyme, a town in Connecticut, US, where it was first discovered in 1975 [26]. Lyme borreliosis is widely distributed, and has been reported in more than 70 countries on five continents. Moreover, the affected area continues to expand and the incidence of this disease is on the rise [5]. It was first reported in China in 1985, in a forest region in Hailin County, Heilongjiang [27]. The peak of incidence of Lyme borreliosis appears to occur from June to August. Its main vectors are Ixodes persulcatus in Northern China,Ixodes granulatus and
C Biomed Central

(c) 2013 Wu et al.; licensee BioMed Central Ltd. This is an Open Access article distributed under the terms of the Creative Commons Attribution License (http://creativecommons.org/licenses/by/2.0), which permits unrestricted use, distribution, and reproduction in any medium, provided the original work is properly cited. 
Table 1 The information of major tick-borne diseases reported in China

\begin{tabular}{|c|c|c|c|c|c|}
\hline Categories & Tick-borne diseases & Causative pathogens & Districts of endemic / case reported/population serological positive & $\begin{array}{l}\text { Prevalence } \\
\text { P/M/A number }\end{array}$ & Reference \\
\hline \multirow[t]{5}{*}{$\begin{array}{l}\text { Zoonotic } \\
\text { bacterial diseases }\end{array}$} & Lyme borreliosis & $\begin{array}{l}\text { Borrelia burgdorferi sensu } \\
\text { lato }\end{array}$ & $\begin{array}{l}\text { Anhui, Beijing, Chongqing, Fujian, Gansu, Guangdong, Guangxi, Guizhou, } \\
\text { Hebei, Heilongjiang, Henan, Hubei, Hunan, Inner Mongolia, Jiangsu, Jiangxi, } \\
\text { Jilin, Liaoning, Ningxia, Shandong, Shaanxi, Shanxi, Sichuan, Tianjin, Tibet, } \\
\text { Qinghai, Xinjiang, Yunnan, Zhejiang }\end{array}$ & 29 & {$[5-8]$} \\
\hline & Q-fever & $\begin{array}{l}\text { Rickettsia burneti } \\
\text { (Coxiella burnetii) }\end{array}$ & $\begin{array}{l}\text { Anhui, Beijing, Chongqing, Fujian, Gansu, Guangdong, Guangxi, Guizhou, } \\
\text { Hainan, Hebei, Heilongjiang, Jiangsu, Jilin, Liaoning, Ningxia, Qinghai, Shandong, } \\
\text { Shaanxi, Taiwan Outbreak in Inner Mongonlia, Sichuan, Xinjiang, Yunnan, Tibet }\end{array}$ & 24 & {$[7,9-11]$} \\
\hline & tularemia & Francisella tularensis & Beijing, Heilongjiang, Inner Mongolia, Qinghai, Shandong, Tibet, Xinjiang, & 7 & {$[10,12,13]$} \\
\hline & North-Asia tick-borne spotted fever & $\begin{array}{l}\text { Rickettsia sibirica, Rickettsia } \\
\text { conorii, Rickettsia akari }\end{array}$ & Beijing, Guangdong, Heilongjiang, Jilin, Liaoning Inner Mongolia, Xinjiang & 7 & {$[7,10]$} \\
\hline & Oriental spotted fever & Richettsia japonica & Hainan & 1 & [14] \\
\hline \multirow[t]{3}{*}{$\begin{array}{l}\text { Zoonotic } \\
\text { viral diseases }\end{array}$} & $\begin{array}{l}\text { Tick-borne encephalitis (Forest } \\
\text { Encephalitis) }\end{array}$ & tick-borne encephalitis virus & $\begin{array}{l}\text { Liaoning, Jilin, Heilongjiang, Inner Mongolia, Xinjiang, Tibet, Yunnan, } \\
\text { Sichuan, Hebei, Greater Khingan Range, Changbai Mountains, the } \\
\text { Altai Mountains, Tianshan Mountain }\end{array}$ & 9 & {$[7,9,15-18]$} \\
\hline & $\begin{array}{l}\text { Crimean-Congo hemorrhagic } \\
\text { fever (Xinjiang hemorrhagic fever) }\end{array}$ & $\begin{array}{l}\text { Crimean-Congo } \\
\text { hemorrhagic fever virus }\end{array}$ & $\begin{array}{l}\text { Cases reported from Xinjiang and Junggar; serological evidence } \\
\text { shown in Qinghai, Yunnan, Sichuan, Inner Mongolia, Anhui, Hainan } \\
\text { and northeast Yili }\end{array}$ & 7 & {$[7,9,16]$} \\
\hline & Colorado fever & Colorado virus & Cases reported in Beijing, Yunnan, Gansu, Hainan, Xinjiang & 5 & [7] \\
\hline \multirow[t]{3}{*}{$\begin{array}{l}\text { Emerging } \\
\text { diseases }\end{array}$} & Novel Bunyavirus infection & Novel Bunyavirus & $\begin{array}{l}\text { Jiangsu, Hubei, Henan, Shandong, Anhui, Liaoning, Zhejiang, Yunnan, Guangxi, } \\
\text { Jiangxi , Shannxi }\end{array}$ & 11 & {$[19,20]$} \\
\hline & Human monocytic ehrlichiosis & $\begin{array}{l}\text { Ehrlichia. canis Ehrlichia } \\
\text { chaffeeusis }\end{array}$ & Guangdong, Guangxi, Hunan, Liaoning, Jilin, Heilongjiang, Xinjiang & 7 & {$[21-23]$} \\
\hline & Human granulocytic anaplasmosis & $\begin{array}{l}\text { Anaplasma } \\
\text { phagocytophilum }\end{array}$ & Anhui, Tianjin, Shandong, Heilongjiang, Inner Mongolia, Xinjiang," Hainan & 7 & {$[21,23,24]$} \\
\hline $\begin{array}{l}\text { livestock parasitic } \\
\text { diseases }\end{array}$ & Piroplasmosis & $\begin{array}{l}\text { Theileria luwenshuni Theileria } \\
\text { uilenbergi Theileria sinense } \\
\text { Babesia motasi }\end{array}$ & Qinghai, Gansu, Ningxia, Sichuan, Yunnan & 5 & [25] \\
\hline Spirochetosis & Tick-borne relapsing fever & Borrelia persica & Beijing, Guangdong, Heilongjiang, Jilin, Liaoning, Inner Mongolia, Xinjiang & 7 & {$[7,9]$} \\
\hline
\end{tabular}


Ixodes sinensis in Southern China, and Haemaphysalis bispinosa ticks may act as the vector in Southern China [6,28]. Human cases of Lyme borreliosis have been confirmed in 29 provinces/municipalities. As demonstrated by its occurrence, its natural foci are present in at least 19 provinces/municipalities in China (Table 1). The major endemic areas in China are forests in the Northeast and Northwest and some areas in North China [29]. In Heilongjiang, Jilin, Liaoning, and Inner Mongolia, over 3 million people suffer tick bites annually, of those, approximately 30,000 people become infected with Lyme borreliosis; approximately $10 \%$ of the new cases may turn into chronic infections over 2 to 17 years without treatment [7]. It was reported that the serological positivity of LD was $1.06 \sim 12.8 \%$ in the 30,000 people randomly sampled (from approximately $20 \mathrm{P} / \mathrm{A} / \mathrm{M}$ ), with a mean positivity rate of $5.06 \%$ overall and $5.33 \%$ in the forests; the morbidity was $1.16 \sim 4.51 \%$ in the forests of Northeastern China, with a mean morbidity of $2.84 \%$ [29].

\section{Tick-borne Encephalitis}

Tick-borne Encephalitis (TBE), also known as Forest Encephalitis in China, is an acute infectious disease of the nervous system caused by the TBE virus (TBEV). This virus was first isolated from patients using mouse inoculation by Tkachev in 1936 [30]. In China, TBE was first observed in 1942, and TBEV was first isolated from patients and ticks in 1952 [31]. Among the three subtypes of TBEV, the European, the Siberian, and the Far-Eastern subtype, the latter is endemic in North China and is also present in Western and Southwestern China [15]. The main vector species in Northern China is Ixodes persulcatus and in Southern China is Ixodes ovatus [15,31]; in rare cases, Dermacentor silvarumhas has also been identified as a carrier of TBEV [15].

In China, TBE mostly occurs sporadically from May to August, and reaches a peak during late May and early June [31]. The distribution of TBE is closely related to the distribution of the tick vectors [16]. Two natural foci for TBE exist in mainland China, the Northeast focus (Inner Mongolia, Heilongjiang, Jilin) and the Xinjiang focus [16]. Serological evidence of TBEV in 9 provinces / municipalities of Western and Southwestern China also exists (Table 1). From 1980 to 1998, 2202 cases of TBE were recorded, whereas from 1995 to 1998, only 420 infections were diagnosed [15]. Based on the statistical analysis of TBE incidence from 1952 to 1998, it appears that a peak has occurred every 5 to 7 years [31]. The TBE incidence has obvious occupational characteristics and the occupational distribution has changed significantly in recent decades. For example, the proportion of forestry workers has declined, while the proportions of farmers, students, and domestic workers have increased [32]. With the development of tourism and the disruption of forest ecological environments in recent years, the prevalence of the disease is on the rise [9].

\section{Crimean-Congo hemorrhagic fever}

Crimean-Congo hemorrhagic fever (CCHF), also known as Xinjiang hemorrhagic fever in China, is caused by infection with a tick-borne virus (Nairovirus) in the family Bunyaviridae. It is widely distributed in Asia, Africa, and Europe, with a mortality of approximately 3-30\% [33]. Its peak of incidence occurs from April to May [9]. CCHF was first described in the Crimea Peninsula of the Ukraine in 1944-1945 [34]. The virus was isolated from the blood and tissues of patients by intracerebral inoculation of suckling mice in 1967, and the virus was later shown to have the same antigenicity and biological characteristics as the Congo virus, which was isolated in 1956 from a febrile patient in Belgian Congo (now the Democratic Republic of the Congo). This led to the virus being called Crimean hemorrhagic fever-Congovirus, and later Crimean-Congo hemorrhagic fever virus [34].

Crimean-Congo hemorrhagic fever first occurred in 1965 in Bachu, Xinjiang, with 10 deaths in 11 infected patients; from 1965 to 2002, 230 cases were reported from Bachu County, with an average annual incidence of 6 [16,35]. Since 2003, no cases have been reported from Xinjiang. Another record CCHF outbreak occurred in the Junggar Basin in 1997, with 26 cases occurring within 45 days, including four deaths [35].

To date in China, CCHF cases have only been reported in Xinjiang and Jungar, while antibody-positive cases have been reported in 7 provinces /municipalities (Qinghai, Yunnan, Sichuan, Inner Mongolia, Anhui, Hainan, and Northeast Yili) (Table 1) [16]. The natural foci of CCHF are confirmed to be present in Tarim Basin, Junggar Basin, Tarim River, and the Yili River Valley border in Xinjiang province, Tengchong, Xundian, Xishuangbanna, and Menglian in Yunnan province, the Inner Mongolia Autonomous Region, as well as Sichuan, Hainan, Anhui, and Qinghai provinces [16,35].

As a disease with natural foci in deserts and pastures, CCHF is transmitted mainly by Hyalomma asiaticum in China, though Ixodes spp. may act as a carrier in some cases [35]. Sheep and hares (Lepus yarkandensis) in pastures in the epidemic area are its main source of infection, but patients with acute infection can also be a source; pathogens can be persist in ticks for several months and can be transmitted transovarially [9].

\section{Q-fever}

Q-fever is an acute natural focal disease caused by the Gram-negative bacterium Coxiella burnetii. It was first observed in 1935 in Australia and described in 1937 [36]. Initially reported in China in 1950, Q-fever naturally spreads among wild animals (rodents) and livestock [9]. Its 
pathogens can persist in ticks for a long period of time and can be spread through eggs. Natural infections of Ixodes persulcatus, Ornithodoros papillipes, Haemaphysalis campanulata, Haemaphysalis asiaticum, Hyalomma asiaticum kozlovi, and Rhipicephalus microplus have been observed in endemic areas [9]. In recent years, new reports revealed that Q-fever may be caused by the transmission of Coxiella burnetii through other methods aside from vector ticks [36-39]. Unengorged ticks of the genus Dermacentor collected from endemic areas in Southern Germany were detected to be negative for $C$. burnetii using a specific nested PCR [37]. The same result was also reported in 887 adult Ixodes ricinus collected from 29 different localities in Southern and Central Sweden [38]. C. burnetii has been reported in less than $2 \%$ of $I$. ricinus in Europe [39]. Though C. burnetii bacteria were detected in more than 40 tick species (mainly of the genera Ixodes, Rhipicephalus, Amblyomma, and Dermacentor), C. burnetii is easily transmitted to healthy individuals via dust or aerosols. Thus ticks may not be a necessary vector for C. burnetii transmission [36]. After all, there is no good evidence that Q-fever is regularly transmitted to humans by tick-bite.

As confirmed by seroepidemiological surveys and cases, Q-fever is currently distributed in 24 provinces/municipalities in China, and outbreaks have been documented in Inner Mongonlia, Sichuan, Xinjiang, Yunnan, and Tibet (Table 1).

\section{Tularemia}

Tularemia, caused by Francisella tularensis, is widely distributed, with epidemics in Europe, Asia, and North America. The first case of tularemia was observed in Tulare county, California, US in 1912 [40]. Its natural foci are limited to the Northern Hemisphere [40] In China, the causative agent was first isolated from ground squirrels in 1957, and the first case of human infection was reported in Heilongjian in 1959 [12]. Later, natural foci were reported to exist in Tibet, Xinjiang, and Gansu [12]. Tularemia cases have mainly been reported in 7 provinces/municipalities of Beijing, Heilongjiang, Inner Mongolia, Qinghai, Shandong, Tibet, and Xinjiang $[10,12,13]$ (Table 1). In 1986, 31 cases of human infection were reported in a meat processing plant in Shandong province; since then, no further cases have been reported in China [12].

Two tick species, Dermacentor silvarum and Ixodes persulatus were reported to harbor the pathogen of tularemia (F. tularensis subsp. Holarctica) in the natural environment, indicating these two tick species might have a role in tularemia existence in China [10]. Rodents and wild animals are its main source of infection, and infection generally occurs in spring and early summer. Pathogens can survive in ticks for 200-700 days [12].

\section{North-Asia tick-borne spotted fever}

North-Asia tick-borne spotted fever (NATBSF) is also known as Siberian tick-borne typhus, North Asian tickborne rickettsiosis, North Asian tick typhus, and North Asia Fever. Its causative agent is Rickettsia sibirica, and small rodents are its main source of infection. This tickborne disease was first described in 1936 in Russia [41]. Since this type of infection is common in many republics of North Asia, much effort has been invested into the studies of NATBSF [41]. An anti-Rickettsia sibirica antibody was first detected in the serum of humans and animals in Inner Mongolia in 1958 [42]. The first case was observed in Hulin city, Heilongjiang province in 1962, where the HL-84 strain of Rickettsia sibirica was first isolated from a wild rodent, Microtus fortis. Later, the Rickettsia sibirica JH-74 strain was isolated from Dermacentor nuttalli in 1974 in Jinghe county, Xinjiang autonomous region, and the An-84 strain was isolated from a patient in 1984 [42]. Dermacentor nuttalli is the main vector for North-Asia TBSF; however, Dermacentor marginatus, Dermacentor sinicus, Derraacentor silvarum and Haemaphysalis yeli can also be vectors for the disease [42]. Its pathogens can be passed through eggs and can survive for two years in ticks. Because methods for diagnosing this disease are not yet standardized, its prevalence in China has yet to be determined; however, cases have been reported in 7 provinces/municipalities of Northern Heilongjiang, Inner Mongolia, Xinjiang, Beijing, Guangdong, Jilin, and Liaoning (Table 1). The natural foci have been reported to exist in most of Northern China (at longitude $90^{\circ} \sim 135^{\circ}$ East and latitude $40^{\circ} \sim 50^{\circ}$ North); serologic clues have also been found in the serum of humans and rodents in parts of Southern China [42].

\section{Emerging tick-borne diseases in China Human monocytic ehrlichiosis (HME)}

Human monocytic ehrlichiosis (HME) is an emerging zoonosis, which was first described in the United States in 1987, and the first case of HME was documented in 1991 in the United States; the causative agent is Ehrlichia chaffeensis, which is an obligate intracellular pathogen affecting monocytes and macrophages [43]. Frequent symptoms of this disease are fever, chills, headache, myalgia, nausea, rash, leukopenia, thrombocytopenia, elevated serum aminotransferase levels, and elevated creatinine levels; the case-fatality rate is approximately $1.9 \%$ or higher [43].

Since the first case of HME was observed in 1999 in China, the epidemic situation of HME has been investigated in North and South China. The bacterium Ehrlichia chaffeensis has been detected with serological and PCR detection methods among people in Xinjiang, Inner Mongolia, Heilongjiang, Guangdong, Guangxi, Fujian, and Yunnan, 7 provinces /municipalities [44] (Table 1), and 
the vectors are reported to be $A$. testudinarium, $H$. yeni, D. silvarum [21].

\section{Human granulocytic anaplasmosis}

Human granulocytic anaplasmosis (HGA) is another emerging tick-borne zoonosis, which was first reported in the United States in 1990 and in Europe in 1997 [45]. As the causative rickettsia was reclassified from the genus Ehrlichia to Anaplasma phagocytophilum, the disease name was changed from human granulocytic ehrlichiosis to HGA in $2001[22,45]$. The pathogen causes the disease by infecting human neutrophils $[21,46]$. The symptoms of HGA are similar to HME, and deaths from HGA are approximately $0.6 \%$ of those infected and typically involve those immunocompromised individuals, usually 10 or more days after disease onset [43,46].

The first case of human HGA caused by Anaplasma phagocytophilum was identified in Anhui in 2006, which eventually resulted in an outbreak and included 1 index case and 9 secondary infection cases probably nosocomially acquired through cutaneous or mucous membrane contact with blood or bloody respiratory secretions of the index case [45]. Such cases, including deaths, were reported in 7 P/A of Anhui, Tianjin, Shandong, Heilongjiang, Inner Mongolia, Xinjiang, and Hainan; Ixodes persulcatus, Haemaphysalis longicornis, and Haemaphysalis concinna are suspected as the main vectors of the disease in China, but detailed transmission evidence is still unavailable [21,23,24] (Table 1).

\section{Novel bunyavirus infection}

A hemorrhagic fever-like illness caused by a novel bunyavirus was reported in China recently. This illness was given the name of Fever, Thrombocytopenia and Leukopenia Syndrome (FTLS) or Severe Fever with Thrombocytopenia (SFTS); the causative virus was determined to be the Huaiyangshan virus (HYSV), Henan Fever virus (HNFV), FTLS virus (FTLSV), or SFTS virus (SFTSV) [19,20,47,48].

First emerging in Henan province in 2007, and again between 2008 and 2010, cases of a life-threatening disease with sudden fever, thrombocytopenia, and leukopenia (defined as FTLS) were reported. Patients reported a history of tick bites, suggesting this disease could be infectious or tick-transmitted [47]. Many patients were previously diagnosed with human granulocytic anaplasmosis (HGA); however, only 24 of 285 (8\%) had a confirmed HGA infection [47]. In this case, other pathogens aside from Anaplasma phagocytophilum may contribute to FTLS. A novel bunyavirus was observed in some cases, but only in clinical samples assessed with illumina sequencing. Further isolation of the virus and epidemiologic investigation confirmed that the novel bunyavirus was associated with FTLS, and was almost sequence identical (99\% identity) to SFLV $[19,47]$.
Between late March and mid-July 2009, an infectious disease emerged in rural areas of Hubei and Henan provinces; patients presented with symptoms of fever, thrombocytopenia, gastrointestinal symptoms, leukocytopenia, and the illness had an unusually high initial case fatality rate of $30 \%$ (the mortality of all infections is between $8 \%$ and 16\%) $[19,20]$. As the disease was characterized by acute fever and thrombocytopenia, it was defined as SFTS [19]. A few months later, a novel bunyavirus was isolated from a patient's blood during the outbreak of SFTS in Xinyang City in Henan province in 2009 [19,20].

By the end of 2011, SFTS had been reported in 11 provinces, including Henan, Hubei, Anhui, Shandong, Jiangsu, Zhejiang, Liaoning, Yunnan, Guangxi, Jiangxi, and Shaanxi (Table 1) [19,20]. As of August 2011, a total of 622 SFTS cases had been reported throughout China, mainly in Henan, Hubei, Shandong, Anhui, Liaoning, Jiangsu, and Zhejiang [1]. A number of human infection clusters have also been identified, suggesting the possibility of humanto-human transmission $[47,49]$.

Most patients affected with SFTS lived in hilly areas or dense jungle areas and had a history of outdoor work; a small number of the patients had a history of tick bites $[1,31]$. Previous studies have detected SFTSV in Haemaphysalis longicornis and Rhipicephalus microplus ticks collected from a number of domestic animals, including cattle, buffalo, goats, cats and dogs [48]. Natural hosts remain to be further determined, but serological positivity has been observed in dogs, cattle, sheep, and other livestock in villages where the patients lived [1].

Many questions related to SFTS caused by the new bunyavirus remain unanswered, such as host animal, route of transmission, clinical classification, pathophysiological features, pathogenesis, and clinical treatment [1].

\section{Conclusions}

The incidence and prevalence of vector-borne diseases have regional features in spatial distribution, and the relative distribution of tick-borne diseases in China is shown in Figure 1. A high prevalence of tick-borne diseases exists in Northern China in areas such as Xinjiang, Inner Mongolia, Heilongjiang, Liaoning, Jilin, and in Northeastern China in places like Yunnan. The major tick-borne diseases in high-incidence areas include Lyme borreliosis, Q-fever, and TBE (Figure 2). Other tick borne diseases that are not frequently reported in China include Colorado fever, piroplasmosis, and oriental spotted fever (Table 1).

Several reasons for the wide dissemination of tick-borne diseases throughout China exist. First, ticks of numerous species are widely distributed, with diverse living habits and numerous hosts, including birds, reptiles, and mammals. Secondly, the vast territory, complex geography, 


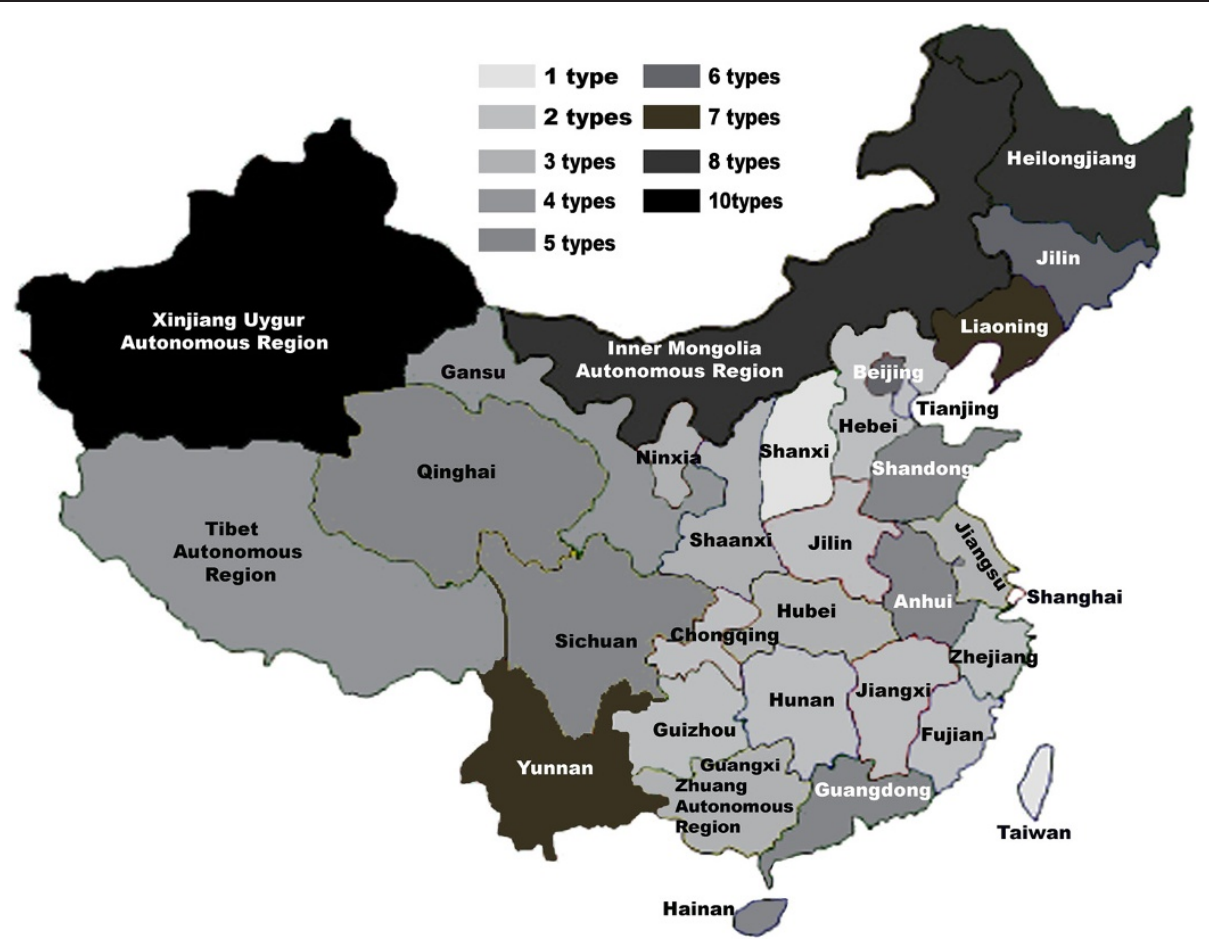

Figure 1 Distribution of tick-borne diseases across China. The tick-borne diseases are highly prevalent in North of China, including Xinjiang Uygur, Inner Mongolia, Heilongjian, Liaoning, Jilin, Beijing provinces/ autonomous regions/ municipalities (P/A/M), as well as Northeastern China including Yunnan province. The corresponding vector borne diseases reported in these P/A/M are indicated in Figure 2.

climate variability, and diverse ecological environments in China provide various habitats for ticks. Thirdly, the rapid development of international and inter- regional exchange has created favorable conditions for the spread of tickborne diseases. Finally, the epidemic area of tick-borne disease is gradually expanding along with changes and ecological damage of the forest environment.
Continuous efforts are still required for the prevention and treatment of tick-borne diseases in China. Distribution of all species of ticks across China should be investigated as thoroughly as possible, so that targeted destruction of ticks can be carried out during their active seasons. Research on the rapid diagnosis of tick-borne diseases and mechanisms of pathogen-transmission needs to be enhanced. More

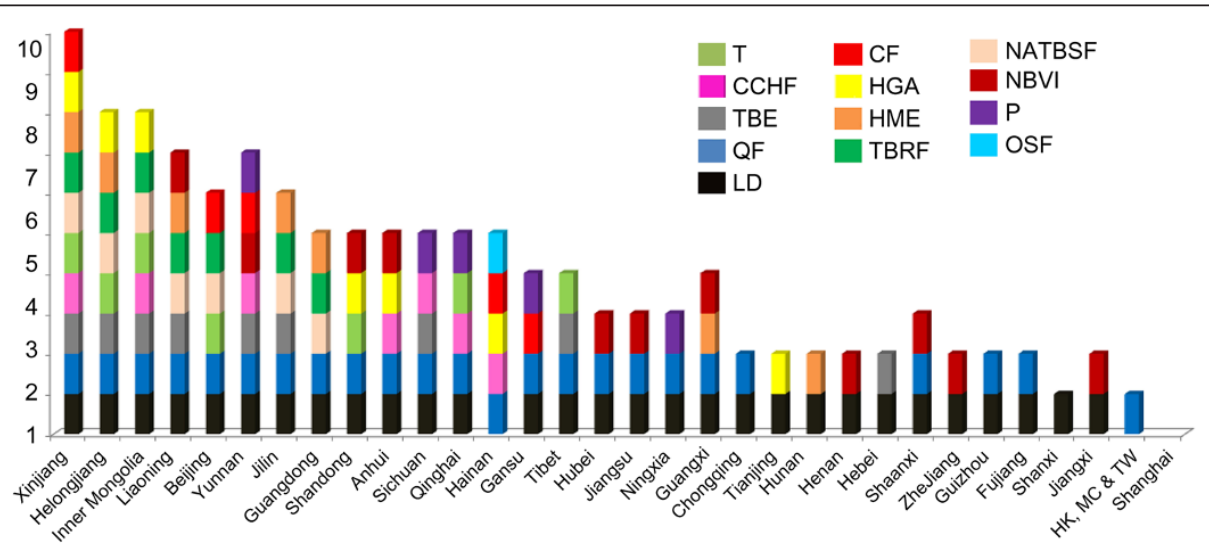

Figure 2 Types of tick-borne diseases reported in China's provinces/ autonomous regions/municipalities (P/A/M). There are more than 13 types of tick-borne diseases are reported in different provinces/autonomous regions/municipalities in China, including TBE (tick-borne encephalitis/ Forest Encephalitis in China), CCHF (Crimean-Congo hemorrhagic fever/Xinjiang hemorrhagic fever in China), CF (Colorado fever), LB (Lyme borreliosis), QF (Q-fever), T (tularemia), NATBSF (North-Asia tick-borne spotted fever), TBRF (Tick-borne relapsing fever), HGA (human granulocytic anaplasmosis), HME( human monocytic ehrlichiosis), NBVI ( Novel Bunya virus infection), P (piroplasmosis), and OSF (oriental spotted fever). 
effective drugs and vaccines against tick-borne diseases are needed and new tick prevention methods must be developed. Finally, integrated biological control of ticks will bring efficient, high-speed, long-term, and pollution-free effects in China.

\section{Competing interests}

None declared.

\section{Authors' contributions}

X-BW: Manuscript drafting. R-HN: Data collection and manuscript drafting. S-SW: Data collection and figure creation. J-SZ: Manuscript proofreading. H-JP: Manuscript drafting, data proofing and manuscript submission. All authors read and approved the final version of the manuscript.

\section{Acknowledgement}

This work is supported by grants from the National Natural Science Foundation of China (No. 81071377, 81271866), Guangdong Province talent introduction of special funds (2011-67), Guangdong provincial key scientific and technological project (2011B010500003), the Guangdong Province College Students Renovation Experimental Program (1212111020).

\section{Author details}

'Department of Epidemiology, School of Public Health and Tropical Medicine, Southern Medical University, Guangzhou, Guangdong 510515, China. ${ }^{2}$ Department of Pathogen Biology, School of Public Health and Tropical Medicine, Southern Medical University, Guangzhou, Guangdong 510515, China. ${ }^{3}$ Department of Biochemistry, Virginia Tech, 311 Engel Hall, Blacksburg, VA 24061, USA.

Received: 29 March 2013 Accepted: 8 April 2013

Published: 23 April 2013

\section{References}

1. Zhang SH: The latest research progress of tick and the tick-borne diseases. Anhui Journal of Preventive Medicine 2012, 18:45-48.

2. Wang GL, Huang J, Gong XH: Aishajiang.Abula: Hard tick and tick-borne diseases. Xinjiang Xu Mu Ye 2010, 9:48-50.

3. Estrada-Peña A, Ayllón N, de la Fuente J: Impact of Climate Trends on Tick-Borne Pathogen Transmission. Front Physiology 2012, 3:64 doi:10.3389/fphys.2012.00064

4. Zhao JW, Wang H-Y, Wang Y: Regional distribution profiles of tick-borne pathogens in China. Chinese Journal Biology and Control 2012, 5:445-447.

5. Hein S, Agnetha H, Fedor G, Willem T, Frans J, van Vliet AJH, van Ballegooijen M, van der Giessen J, Katsuhisa T: Circumstantial evidence for an increase in the total number and activity of borrelia-infected ixodes ricinus in the Netherlands. Parasites \& Vectors 2012, 5:294.

6. Niu QL, Yin H, Luo JX: Progress on Lyme disease in China. Progress in Veterinary Medicine 2009, 30:89-93.

7. Wang YY, Li J, Wang S, Hu M, Lu FL: Tick-borne infectious diseases. Infectious Disease Information 2011, 1:58-61.

8. Pan L, Chen Z, Huang Y, Chen Y, Yu E: Investigation on the Host Animal and Transmission Vector of Lyme Disease in Fujian Province. Chinese Journal of Vector Biology and Control 1996, 6:437-439.

9. Zhou JP, Zhang WY, Ju HB: Tick and tick-borne infectious diseases. Shanghai Journal of Animal Husbandry and Veterinary Medicine 2011, 4:12-14.

10. Zhang F, Liu W, Wu XM, Xin ZT, Zhao QM, Yang H, Cao WC: Detection of Francisella tularensis in ticks and identification of their genotypes using multiple-locus variable-number tandem repeat analysis. BMC Microbiol 2008, 8:152. doi:10.1186/1471-2180-8-152.

11. Liu Y, Zhang Y: The Study Progress of Q Fever and Ehrlichiosis. Medical Recapitulate 2008, 6:864-867.

12. Zhang F, Liu W, He J, Duan Q, Wu X, Zhao Q, Zhang P, Yang H, Cao W: Molecular epidemiological investigation on Francisella tularensis infection hosts in northern China. Bullitin of Academy of Military Medical Science 2006, 2:131-134.

13. Kong ZM, Chen GS, Jin GY, Shi PY, Zhou XR, Lai XQ: Investigations on ticks and tick-borne natural focal infections in Xinjiang. Bulletin of Disease Control and Prevention 1986, 3:1-4.
14. Yan Y: Takahiro Uchida: Sequence Analysis of the Amplified Product from Rchettsia japonica DNA and Its Application for the Identification of Tick Vectors. Chinese Journal of Zoonoses 1995, 3:2-5.

15. Lu Z, Bröker M, Liang G: Tick-borne encephalitis in mainland China. Vector Borne Zoonotic Dis 2008, 8:713-720.

16. Gao X, Nasci R, Liang G: The Neglected Arboviral Infections in Mainland China. PLoS Neglected Tropical Diseases 2010, 4:e624. doi:10.1371/journal. pntd. 0000624

17. Suss J: Epidemiology and ecology of TBE relevant to the production of effective vaccines. Vaccine 2003, 21(Supp 1):19-35.

18. Lindquist L: Tick-borne encephalitis (TBE) in childhood. Acta Paediatrica 2008, 5:532-4. doi:10.1111/j.1651-2227.2008.00761.x.

19. Yu XJ, Liang MF, Zhang SY, Liu Y, Li JD, Sun YL, Zhang L, Zhang QF, Popov $V L$, Li C, et al: Fever with thrombocytopenia associated with a novel bunyavirus in China. New England Journal of Medicine 2011, 364:1523-1532.

20. Lam TT, Liu W, Bowden TA, Cui N, Zhuang L, Liu K, Zhang YY, Cao WC, Pybus OG: Evolutionary and molecular analysis of the emergent severe fever with thrombocytopenia syndrome virus. Epidemics 2013, 1:1-10. doi:10.1016/j.epidem.2012.09.002.

21. Wen B, Cao W, Pan H: Ehrlichiae and ehrlichial diseases in china. Annals of the New York Academy of Science 2003, 990:45-53.

22. Youmna M'g, Hèla Y, Abderazek G, Ali B: Anaplasma phagocytophilum in horses and ticks in Tunisia. Parasites \& Vectors 2012, 5:180.

23. Zhang L, Cui F, Wang L, Zhang L, Zhang J, Yang S, Han J: Anaplasma phagocytophilum and Ehrlichia chaffeensis in Yiyuan county, Shandong. Infectious Disease Information 2009, 1:21-25.

24. Cao WC, Zhao QM, Zhang PH, Dumler JS, Zhang XT, Fang LQ, Yang H: Granulocytic ehrlichiae in Ixodes persulcatus ticks from an area in China where Lyme disease is endemic. J Clin Microbiol 2000, 38:4208-4210.

25. Niu Q, Guan G, Liu Z, Ma M, Li Y, Liu A, Ren Q, Liu J, Luo J, Yin H: Simultaneous detection of piroplasma infections in field Haemaphysalis qinghaiensis ticks by reverse line blotting. Exp Appl Acarol 2012, 2:123-132.

26. Allen CS, Stephene EM, John AH, Shaun R, Philip WA, Warren AA: Erythema Chronicum Migrans and Lyme Arthritis: The Enlarging Clinical Spectrum. Annals of Internal Medicine 1977, 6:685-698.

27. Meng XH, Liu ZJ, Huang FS: Ticks in China such as Lyme disease media research situation. Health helminthic machinery 2004, 3:137-140.

28. Sun Y, Rongman X, Cao W: Ixodes sinensis: Competence as a vector to transmit the Lyme disease spirochete Borrelia garinii. Vector Borne Zoonotic Dis 2003, 1:39-44.

29. Wu GH, Jiang ZK: Lyme disease and prevention and control of ticks. Chinese Journal of Hygienic Insecticides 2007, 5:312-314.

30. Dumpis U, Crook D, Oksi J: Tick-borne encephalitis. Clin Infect Dis 1999, 4:882-890.

31. Ma XY, Peng WM, Gao X: Review on tick-borne encephalitis research. Chinese Journal of Virology 2004, 2:190-192.

32. Zhang HD, Zhang ZX, Wang YM: Analysis of the trend of tick-borne encephalitis epidemic situation in Heilongjiang province. Disease Surveillance 2000, 2:57-58.

33. Zhu XG, Yang YH, Zhu QY: The research progress of Xinjiang hemorrhagic fever virus. Progress in Microbiology and Immunology 2005, 4:52-55.

34. Ergonul O: Crimean-Congo haemorrhagic fever. Lancet Infectious Diseases 2006, 6:203-214

35. Wang YX, Liu Y, Liao JH: Tick borne disease - xinjiang hemorrhagic fever research progress. Shanghai animal husbandry and veterinary communication 2006, 3:14-15.

36. Chmielewski T, Tylewska-Wierzbanowska S: Q fever at the turn of the century. Pol J Microbiol 2012, 2:81-93.

37. Pluta S, Hartelt K, Oehme R, Mackenstedt U, Kimmig P: Prevalence of Coxiella burnetii and Rickettsia spp. in ticks and rodents in southern Germany. Ticks Tick Borne Dis 2010, 3:145-147. doi:10.1016/j. ttbdis.2010.04.001.

38. Wallménius K, Pettersson JH, Jaenson TG, Nilsson K: Prevalence of Rickettsia spp., Anaplasma phagocytophilum, and Coxiella burnetii in adult Ixodes ricinus ticks from 29 study areas in central and southern Sweden. Ticks Tick Borne Dis 2012, 2:100-6. doi:10.1016/j. ttbdis.2011.11.003.

39. Astobiza I, Barral M, Ruiz-Fons F, Barandika JF, Gerrikagoitia X, Hurtado A, García-Pérez AL: Molecular investigation of the occurrence of Coxiella burnetii in wildlife and ticks in an endemic area. Vet Microbiol 2011, 147:190-194. 
40. Farlow J, Wagner DM, Dukerich M, Stanley M, Chu M, Kubota K, Petersen J, Keim P: Francisella tularensis in the United States. Emerg Infect Dis 2005, 12:1835-1841

41. Lewin MR, Bouyer DH, Walker DH, Musher DM: Rickettsia sibirica infection in members of scientific expeditions to northern Asia. Lancet 2003, 9391:1201-1202.

42. Chen M, Fan M: A review on the research of North-Asia tick-borne spotted fever. Chinese public health 1997, 6:373-376.

43. Dahlgren FS, Mandel EJ, Krebs JW, Massung RF, McQuiston JH: Increasing incidence of Ehrlichia chaffeensis and Anaplasma phagocytophilum in the United States, 2000-2007. Am J Trop Med Hyg 2011, 1:124-131.

44. Gao DQ, Cao WC, Zhang X, Zhan Q, Zhu J, Chen S, Dai Q, Zhang P, Yang H: Investigations on Human ehrlichiainfectious people in Daxingan Mountain. Chines Journal of Epidemiology 2001, 2:137-141.

45. Zhang L, Liu Y, Ni D, Li Q, Yu Y, Yu XJ, Wan K, Li D, Liang G, Jiang X, Jing H, Run J, Luan M, Fu X, Zhang J, Yang W, Wang Y, Dumler JS, Feng Z, Ren J, $\mathrm{Xu}$ J: Nosocomial transmission of human granulocytic anaplasmosis in China. JAMA 2008, 300:2263-2270. doi:10.1001/jama.2008.626.

46. Krause PJ, Wormser GP: Nosocomial transmission of human granulocytic anaplasmosis? JAMA 2008, 300:2308-2309. doi:10.1001/jama.2008.665.

47. Xu B, Liu L, Huang X, Ma H, Zhang Y, Du Y, Wang P, Tang X, Wang H, Kang $K$, et al: Metagenomic analysis of fever, thrombocytopenia and leukopenia syndrome (FTLS) in Henan Province. China: discovery of a new bunyavirus. PLoS Pathogens 2011, 7:e1002369. doi:10.1371/journal. ppat.1002369.

48. Zhang YZ, Zhou DJ, Qin XC, Tian JH, Xiong Y, Wang JB, Chen XP, Gao DY, He YW, Jin D, et al: The ecology, genetic diversity, and phylogeny of Huaiyangshan virus in China. Journal of Virology 2012, 86:2864-2868.

49. Bao CJ, Guo XL, Qi X, Hu JL, Zhou MH, Varma JK, Cui LB, Yang HT, Jiao YJ, Klena JD, et al: A family cluster of infections by a newly recognized bunyavirus in eastern China, 2007: further evidence of person-to-person transmission. Clinical Infectious Diseases 2011, 53:1208-1214.

doi:10.1186/1756-3305-6-119

Cite this article as: Wu et al:: Distribution of tick-borne diseases in China. Parasites \& Vectors 2013 6:119.

\section{Submit your next manuscript to BioMed Central and take full advantage of:}

- Convenient online submission

- Thorough peer review

- No space constraints or color figure charges

- Immediate publication on acceptance

- Inclusion in PubMed, CAS, Scopus and Google Scholar

- Research which is freely available for redistribution

Submit your manuscript at www.biomedcentral.com/submit

C Biomed Central 